\title{
Pharmacology and Toxicology
}

National Cancer Institute

\section{Source}

National Cancer Institute. Pharmacology and Toxicology. NCI Thesaurus. Code C18222.

The science concerned with drugs together with the science concerned with the detection, chemical composition, and pharmacologic action of toxic substances or poisons and the treatment and prevention of toxic manifestations. 